\title{
Interactional Response During Infants' Aquatic Sessions
}

\section{\begin{tabular}{ll} 
OPEN \\
\hline ACCESS
\end{tabular}}

(c) $(1) \ominus$

Authors

Marta Martins', 2, Aldo Costa ${ }^{3,4}$, Mario J. Costa4, 5, Daniel A. Marinho3, 4D, Tiago M. Barbosa6, 7

\section{Affiliations}

1 Sport Sciences, Polytechnic Institute of Santarém Sport Sciences School of Rio Maior, Rio Maior, Portugal

2 Life Quality Research Centre, CIEQV, Santarem, Portugal

3 Sports Science Department, UBI, Covilha, Portugal

4 Research Centre in Sports, Health and Human Development, CIDESD, Vila Real, Portugal

5 Departement of Sport Sciences, Bragança, Polytechnic Institute of Bragança, Portugal

6 Physical Education \& Sports Science Academic Group, Singapore, National Institute of Education, Nanyang Technological University, Singapore

7 Polytechninc Institute of Braganca, Portugal

Key words

Aquatics, Infant behavior, Baby

$\begin{array}{ll}\text { received } & 11.12 .2019 \\ \text { revised } & 10.06 .2020 \\ \text { accepted } & 15.06 .2020\end{array}$

Bibliography

DOI https://doi.org/10.1055/a-1201-4522

Published online: 2020

Sports Medicine International Open 2020; 4: E70-E75

(c) Georg Thieme Verlag KG Stuttgart · New York

ISSN 2367-1890

\section{Correspondence}

Dr. Marta Martins

Polytechnic Institute of Santarém Sport Sciences, School of

Rio Maior, Sport Sciences, Av Dr Mario Soares

2040-413 Rio Maior

Portugal

Tel.: + 351243999280

martamartins@esdrm.ipsantarem.pt

\section{ABSTRACT}

The aim of study was to assess infants' behaviour during routine swimming sessions using a naturalistic observation method. The study sample included 14 infants ( $13.7 \pm 7.5$ months old) with previous aquatic experience. The frequency of occurrences per unit of time (session) in the different dimensions infant's motor behaviour and social-affective interaction - was registered over the course of two sessions by two independent experts. The behaviours most frequently observed were accompanied displacement (61.1\%) and interaction with others (41.6\%). Submersions or jumps represented only $8.4 \%$ of the session. Implementing a child-centred methodology leads to positive behaviours during this type of sessions, contributing to the child's healthy development.

\section{Introduction}

The participation of infants in aquatic activities has increased remarkably in the last several decades. The proposed aquatic programs are not directed towards teaching infants (generally between 6-36 months) to swim or to prevent drowning. Instead, they should aim to contribute to their sensory and motor development, as demonstrated by previous studies [1-6]. Usually, those types of classes help developing body awareness and encourage autonomy and sociability. The presence of the infant's parents is key to facilitate this process because it gives the child confidence to try out new movements and sensations in a new environment.

Despite differing greatly from each other, the most common pedagogical approaches for water familiarization tend to provide a compromise between the pleasure of being in the water and the effective learning of several basic aquatic skills [7,8]. Aquatic and terrestrial environment-oriented activities present different characteristics. The intensity of effort, as determined by body immersion and position, and water temperature, leads to anxiety and panic (fear) especially in young and inexperienced infants [9].

Previous studies aimed to register the child's experiences during swimming lessons [10-13]. This information gave useful tips and practical implications for swimming teachers, leading to adjustments in session planning considering the level of aquatic competence and infant experience.

More naturalistic observations constitute a valuable comprehensive method in which participants are observed in their natural context avoiding intrusion or interference with the normal course of the events [14].

Using enhanced video recordings and coding of naturalistic observations, our study aimed to describe infants' behaviour during 
routine swimming sessions. The study was carried out in an informal aquatic setting, without manipulation or intervention by observers, but under strict protocols and techniques in order to eliminate limitations and subjectivities.

\section{Materials and Methods}

\section{Participants}

Fourteen infants $13.7 \pm 7.5$ months old and with $7.71 \pm 7.54$ months of experience took part in this study. All parents displayed a good aquatic readiness level (verified by their child's swimming teacher) and were engaged with their infant's swim sessions on a regular basis since the beginning of their baby's swimming sessions in order that the parents' presence might reduce their infant's anxiety level and affect their behaviour.

Infants were selected according to the following criteria: (i) children with weekly participation in all proposed swim sessions (September to December); (ii) all sessions were conducted by the same teacher, specialized in infant swimming; and (iii) all children were accompanied by their parents who showed a good aquatic readiness. The exclusion criteria were: (i) infants who refused their inclusion in the study; (ii) parents without or with poor aquatic adaptation; (iii) infants with some pathology or specific physical conditions; or (iv) infants who did not participate in all the sessions and/or left the sessions earlier.

The study was conducted according to the requirements of the Declaration of Helsinki and meets the ethical standards in sport and exercise science research [15]. Parents gave their formal written consent for the infants to participate.

\section{Study design}

The experimental set included five sessions conducted using a child-centred methodology. The first three sessions aimed at familiarization of the infants with the apparatus and data collection procedures. The remaining two sessions were used for data collection.

The observation procedures were defined and divided according to the most important components [16], because the main goal was to observe the infants' behaviour while they participated in swimming sessions.

The researcher responsible for the video acquisition in this study had a training period prior to the main observation time point, according to other protocols already used in this area [17]. Swimming sessions were performed in an indoor swimming pool 16 meters in length and one meter deep. Water temperature was $31^{\circ} \mathrm{C}$, air temperature $28{ }^{\circ} \mathrm{C}$ with $65 \%$ humidity. All sessions lasted 30 minutes and were conducted by a specialized instructor. Each session's structure was designed according to individual characteristics (e.g. age, motor development level, background experience in swim sessions, etc). Parents stayed close to their infant but allowed them to perform the proposed skills with autonomy. Each swim session comprised four distinct parts: (i) initial part, welcoming routine of infants and adults by the instructor ( 5 minutes); (ii) main part, promoting the stimulation of the motor skills and social aspects (10 minutes); (iii) free period, where infants and adults share non-ori- ented activities together (10 minutes); and (iv) the final part, where infants say good-bye (5 minutes). Auxiliary equipment was used to stimulate the infant to perform the motor skills when necessary.

\section{Measures}

All sessions were recorded with one video camera located 3 meters away, in front of the protocol pool set in order to reduce any change in the infants' behaviour. The camera recorded one baby at a time in the class. The camera position, zoom, and mobility allowed capturing the best perspective of all the emotional state of the babies.

The actions in the recorded video were registered by putting into words every motion expressed in the video. Data was analyzed according to the categorized variable $[16,18,19]$. The order and type of occurrences of different dimensions (motor behaviour and socioaffective) and categories were registered for later analysis. The duration of children's activities were recorded. Problems associated with eventual observational errors and precision accuracy of the experts, despite their ten years of experience in the area and academic qualifications, were minimized by applying the Bellack index (total agreements/total agreements + total disagreements) $\times 100-$ accepting a result equal or superior to eighty percent as the guarantor of reliability [18].

The motor behaviour dimension was split into the following categories: i) child's interaction (with an adult, another child, water or object); and ii) motor skills (vertical and horizontal displacement, displacement with support of an adult or material, submersion, and jumps). The socio-affective dimension was split into the following categories: i) child's eye-gaze direction (to another child, to an adult, to water, to object); and ii) child's emotional expressions (laughing, crying, screaming, passive, disagreeable).

\section{Analysis}

Data are reported as mean \pm standard deviation (SD). All variables were analyzed according to the percentage of occurrence in each dimension and category (child's actions were registered by frequency and not by sequence.

\section{Results}

The Bellack Index was used to assess inter-observer reliability, and the values obtained showed a strong concordance between them ( $\triangleright$ Table 1,1a) because $92 \%$ was the lowest value for the 'Looking at other' category. Also, the intra-observer test demonstrates consistency with a mean of $96 \%$ overall concordance ( $\triangleright$ Table $2,2 a$ ).

The results are expressed as relative percentage and mean value for each variable studied. In general, the accompanied displacements (61.1\%) and interaction with other children (41.6\%) were the most frequent ones ( $\triangleright$ Table 3).

The motor behaviour dimension, and particularly the displacements and interaction categories, were the most frequently observed tasks, whereas other specific tasks such as submersion or jumps represent only $8.4 \%$ of the session. In terms of the socio-affective dimension, all the key attention foci of the infants were recorded. Children's gaze was mainly directed at objects $(30.7 \%)$, followed by at their parents (14.1\%). Indifference (11.5\%) and laughter (10.4\%) were dominant during the session. ( $\triangleright$ Table 4 ) 

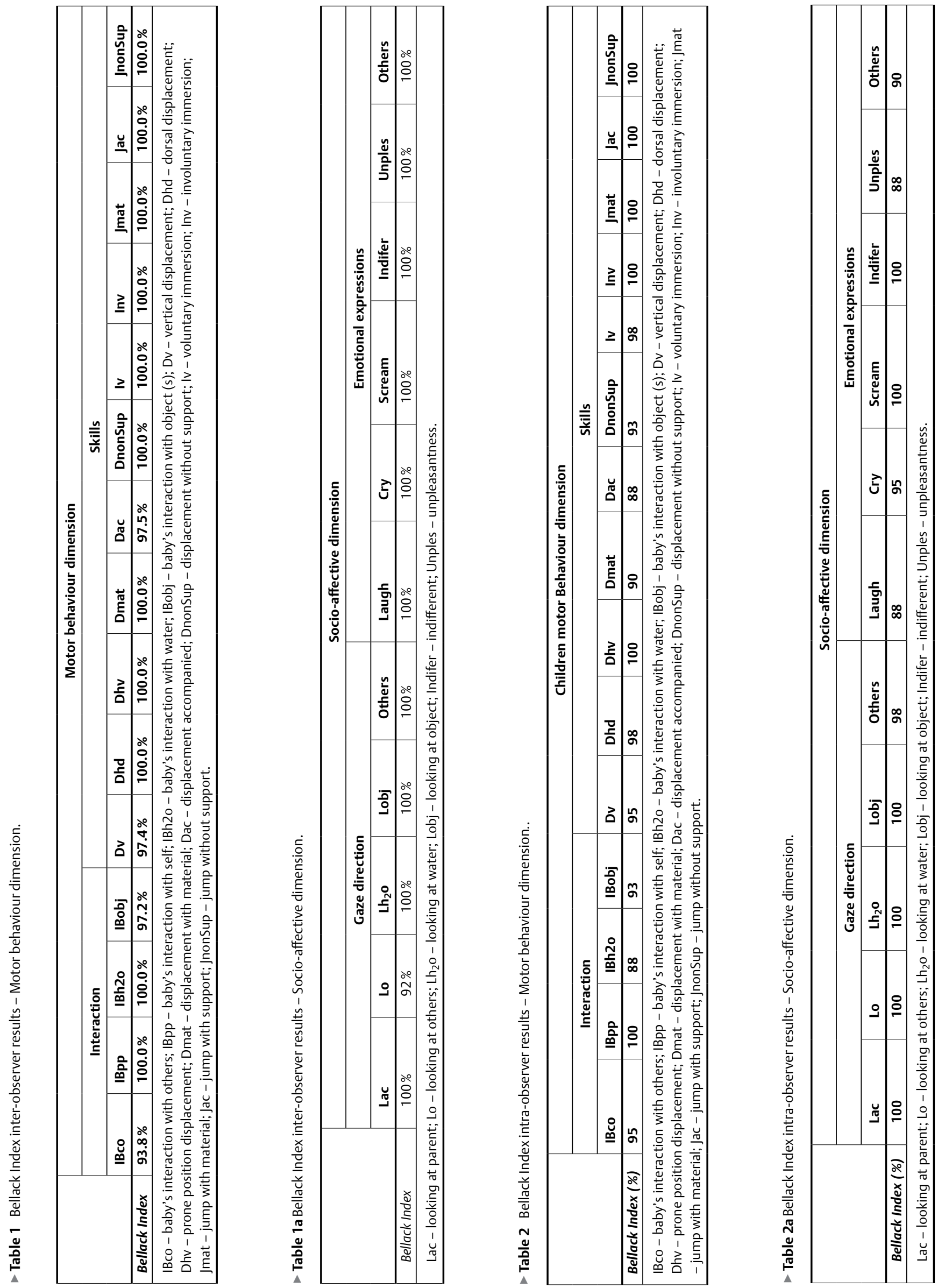


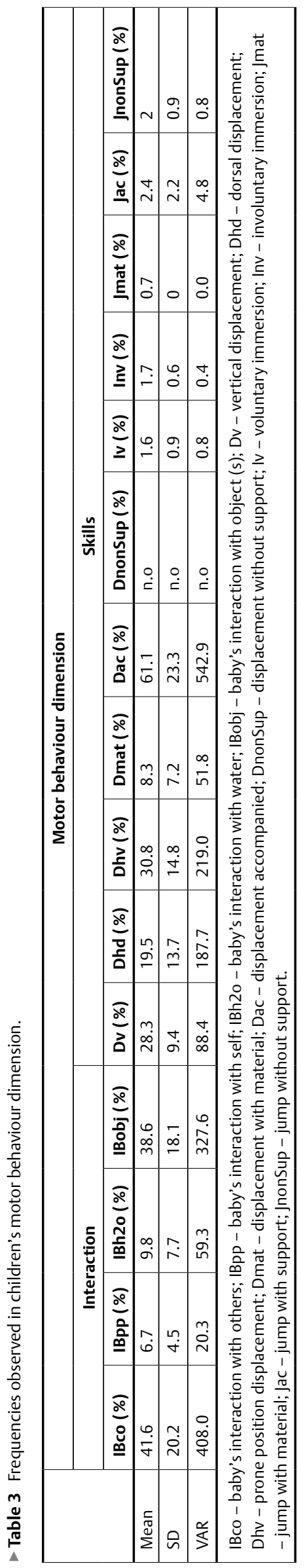

\section{Discussion and Conclusions}

The aim of this study was to collect and register data of infants' behaviour during a swimming session through natural observation.

Displacements and interaction categories were the most frequently observed and registered during the intervention. Also, there is an emergent need to tailor the tasks so that children will not spend most of the session in a task that puts them in constant physiological overload [20,21].

In another study performed simultaneously [20], six of the fourteen children showed a higher HR in tasks such as dorsal displacement, vertical displacement, and prone position displacement, which comprise up to $78.6 \%$ of the session. Moreover, the majority of the children obtained their maximal HR (132.43 \pm 12.720 bpm) in the prone position displacement. A positive significant correlation between $H R$ and the time spent in a vertical position $(r=0.99, p<0.05)$ was found.

The submersion skill, which might be easily associated with this kind of activity and therefore might imply more interest around it, only had a frequency of occurrence in the session of $3.3 \%$.

From these data we were also able to make some individual analyses, which may interestingly lead us to propose a categorization of parents. One child had $100 \%$ of frequency occurrences in the accompanied displacement category, among other similar behaviours, revealing an attachment and constant proximity to his parent that allows us to define this parent as a hyper-protector or super-protector $[22,23]$. This infant was probably more anxious than the rest of the group. The "hyper-protective" classification is currently used in family psychology to categorize parents' behaviour.

The findings of this study demonstrated that the children mainly manifested expressions of indifference or passiveness that might be connected to the enormous amount of stimulus to which the children are exposed, thus bringing them into that state [23]. Several authors [24-28] describe the importance of stimulus and environment to the motor, cognitive, and social development of the child. As a matter of fact, from a social point of view, aquatic programs directed towards this population aim not only to increase the time and quality of the interactions between parents and their child but also to promote or extend the child's first social interactions [29]. Regarding the cognitive aspect of the child's development, we emphasize the importance of aquatic games in creating opportunities for language development and elementary mathematical notions, as evidenced by authors [30], changing the indifferent status to a more active one through tasks that develop cognitive skills.

A child's behaviour is often influenced by the kind of parents involved. In the aquatic environment, although new and discoverable, the child's emotions are often camouflaged and concealed from the naked eye due to the overwhelming atmosphere they are exposed to.

It should be noted that one of the limitations of this study is the difficulty to divide the sample according to previous experience criteria. This can eventually explain the higher SD values obtained in certain variables (baby's interaction with others, baby's interaction with object, vertical displacement, dorsal displacement, prone position displacement, and accompanied displacement). To address this issue, we suggest performing a longitudinal behavioural study with narrower criteria regarding age and previous experience. 
- Table 4 Behavioural frequencies observed in the socio-affective dimension.

\begin{tabular}{|c|c|c|c|c|c|c|c|c|c|c|c|}
\hline & \multicolumn{11}{|c|}{ Socio-affective dimension } \\
\hline & \multicolumn{5}{|c|}{ Gaze direction } & \multicolumn{6}{|c|}{ Emotional expressions } \\
\hline & $\operatorname{Lac}(\%)$ & Lo (\%) & $\operatorname{Lh}_{2} \mathrm{O}(\%)$ & Lobj (\%) & Others (\%) & Laugh (\%) & Cry (\%) & Scream (\%) & Indifer (\%) & Unples (\%) & Others (\%) \\
\hline Mean & 14.1 & 9.5 & 6.6 & 30.7 & 9.8 & 10.4 & 0.7 & 1.8 & 11.5 & 3.8 & 5.9 \\
\hline SD & 9.1 & 5.6 & 3.3 & 18.5 & 9.1 & 6.7 & 0.3 & 1.7 & 6.3 & 4 & $\mathbf{0}$ \\
\hline VAR & 82.8 & 31.4 & 10.9 & 342.3 & 82.8 & 44.9 & 0.1 & 2.9 & 39.7 & 16.0 & 0.0 \\
\hline
\end{tabular}

Lac - looking at parent; Lo - looking at others; Lh $2 \mathrm{O}$ - looking at water; Lobj - looking at object; Indifer - indifferent; Unples - unpleasantness.

In conclusion, we consider that implementing a child-centred methodology leads to positive behaviours during this type of session and contributes to a child's healthy development [31,32].

\section{Acknowledgements}

The authors would like to thank the infants and parents who participated in this study.

\section{Conflict of Interest}

The authors declare that they have no conflict of interest.

\section{References}

[1] Bem T, Cabelguen J, Grillner S et al. From swimming to walking: A single basic network for two different behaviours. Biol Cyber 2003; 88: 79-90

[2] Zhao S, Xie L, Hu H et al. A study of neonatal swimming (water therapy) applied in clinical obstetrics. J Matern Fetal Neonatal Med 2005; 17: 59-62

[3] Courage ML, Reynolds GD, Richards J. Infants attention to patterned stimuli: developmental change from 3 to 12 months of age. Child Dev 2006; 77: 680-695

[4] Moulin JP. Baby swimming: effects of swimming courses on infant development. J Pediatr Pueric 2007; 20: 25-28

[5] Sigmundsson H, Hopkins B. Baby swimming: exploring the effects of early intervention on subsequent motor abilities. Child Care Health Dev 2010; 36: 428-430

[6] JABdS Dias, Ed] Manoel, RBdM Dias et al. Pilot study on infant swimming classes and early motor development. Percept Mot Skills 2013; 117: 950-955. doi: https://doi.org/10.2466/10.25. PMS. $117 \times 30 z 2$

[7] Langendorfer S], Bruya L. Aquatic Readiness: Developing Water Competence in Young Children. Champaign, IL: Human Kinetics; 1995

[8] Langendorfer SJ. Self-agency and swimming: Letting babies be your teachers. International Journal of Aquatic Research and Education: Vol. 11: No. 3 , Article 1. doi: 10.25035/ijare.11.03.01. Available at: https://scholarworks.bgsu.edu/ijare/vol11/iss3/1

[9] Costa M], Barbosa TM, Ramos A et al. Effects of a swimming program on infants' heart rate response. J Sports Med Phys Fitness 2016; 56: 352-358

[10] Latorre-García J, Sánchez-López AM, Baena-García L et al. Physical activity in water to improve the psychomotricity in healthy babies. Babyswimming study protocol. JNNPR 2017; 2: 186-193. doi: https:// doi.org/10.19230/jonnpr.1345
[11] Sigmundsson $\mathrm{H}$, Lorås HW, Haga M. Exploring task-specific independent standing in 3-to 5-month-old infants. Front Psychol 2017; 8: 657

[12] Dalton TC. The ontogeny of vonsciousness. John Dewey and Myrtle McGraw's contribution to a science of mind. J Conscious Stud 1999; 6: 3-26

[13] Richards JE, Gibson TL. Extended visual fixation in young infants: look distributions, heart rate changes, and attention. Child Dev 1997; 68: 1041-1056

[14] Patankar MS, Sabin EJ. The Safety Culture Perspective. In: Salas E, Maurino D, Eds. Human Factors in Aviation. 2nd ed.Cambridge, MA Academic Press; 2010: 95-122. doi: https://doi.org/10.1016/ B978-0-12-374518-7.00004-3

[15] Harriss DJ, Macsween A, Atkinson G. Ethical standards in sport and exercise science research: 2020 update. Int J Sports Med 2019; 40: 813-817

[16] Camerino O. Estudio de la interacción en un grupo de praticantes de actividad física. In: Anguera MT, Ed Observación en deporte y conducta cinestésico-motriz: Aplicaciones. Barcelona: Edicions Universitat Barcelona; 1999: 130-160

[17] Martins M, Silva AJ, Pereira AD et al. Assessment of heart rate in infants from 6 to 36 months old during aquatic activities. Journal of Sports Science and Medicine ISSN 1303-2968. 8:11, p. 137

[18] Anguera MT. La observación.In Rosset CM ed Evaluación psicológica Concepto, proceso y aplicación en las áreas del desarrollo y de la inteligencia. Madrid: Sanz y Torres; 2003: 271-308

[19] Brito AP. Observação directa e sistemática do comportamento. Lisboa: FMH; 1998

[20] Martins M, Silva A, Marinho D et al. Assessment of heart rate during infants' swim session. Int SportMed J 2010; 11: 336-344

[21] Martins M, Silva A, Marinho D et al. Infants' Behaviors During Aquatic Activities. In: Kjendlie P-L, Stallman RK, Cabri ], Eds. XIth International Symposium for Biomechanics and Medicine in Swimming; 2010 Jun 16-19. Oslo, Norway. Oslo: Norwegian School of Sport Science; 2010

[22] Alles-Jardel M. Les interactions parents-jeune enfant dans le milieu aquatique: observation et analyse.In Camus J, Moulin JP, Navarro C, Eds. L'enfant et L'eau. Paris: Harmattan; 1994: 67-81

[23] Moreno JA, Pena L, Castillo M. Manual de actividades acuáticas en la infancia. para bebés y niños hasta seis años. Barcelona: Paidós Ibérica; 2004

[24] Martins M, Moreira A, Silva AJ et al. Caracterização do desenvolvimento de crianças (6-36 meses) participantes em aulas de adaptação ao meio aquático para bebés. Motricidade 2006; 2: 91-98

[25] Damásio A. Descartes' Error: Emotion. Reason, and the Human Brain. New York: Pan Macmillan; 1995

[26] McGraw M. Swimming behaviour of the human infant. J Pediatr 1939; 15: $485-490$

[27] Piaget J, Inhelder B. La Psychologie de l'enfant. Paris: Presses Universitaires de France; 1966 
[28] Vygotsky LS, Leontiev LA. Psicologia e Pedagogia. Lisboa: Estampa; 1977

[29] Jorgensen R. Early years swimming: a way of supporting school transitions? Early Child Dev Care 2016; 186: 1429-1437

[30] Wallon H. A evolução psicológica da criança. Lisboa: Edições 70; 1981
[31] Jorgensen R. Under-fives swimming as a site for capital building: supporting and enhancing the transitions. Aust J Early Child 2012; 37: 127-131

[32] Osnat AE, Ora OP, Saskia DMS. Parental beliefs and practices concerning motor development: Testing new tools. Eur J Dev Psychol 2017; 14: 556-604

\section{Notice}

This article was changed according to the erratum on December 07, 2020.

\section{Erratum}

In the above mentioned article the page numbers were corrected, it must be E70-E75. 